\title{
BEM-ESTAR E PERFIL DE TRABALHADORES TERCEIRIZADOS DA UNIVERSIDADE FEDERAL DE VIÇOSA-UFV
}

\section{WELL-BEING AND PROFILE OF THIRD-PARTY WORKERS AT THE FEDERAL UNIVERSITY OF VIÇOSA-UFV}

\author{
BIENESTAR Y PERFIL DE LOS TERCEROS TRABAJADORES DE LA UNIVERSIDAD \\ FEDERAL DE VIÇOSA-UFV
}

\author{
Marco Aurélio Muniz Corrêa de Carvalho ${ }^{1}$ \\ Amélia Carla Sobrinho Bifano² \\ Márcia Barroso Fontes ${ }^{3}$ \\ Bruno Silva Olher ${ }^{4}$
}

\begin{abstract}
Resumo
O estudo teve por objetivo desenvolver uma caracterização do perfil socioeconômico dos trabalhadores terceirizados em instituições públicas, bem como sua relação com o bem-estar no trabalho na Universidade Federal de Viçosa (UFV). Realizou-se uma breve contextualização histórica sobre a terceirização, seus desdobramentos como a precarização do trabalho e seus efeitos sobre o bem-estar no trabalho, buscando obter dados sobre sua satisfação no trabalho, se os direitos trabalhistas estariam sendo negados, qual a importância do trabalho e a existência destes direitos para estes trabalhadores. A análise foi realizada com 90 trabalhadores terceirizados em 2013 do campus, a partir de indicadores coletados por meio de um questionário sobre o perfil socioeconômico e a apreensão do bem-estar dos trabalhadores, a partir de parâmetros da literatura. Os dados foram analisados de forma estatística-descritiva no software especializado STATA. Observou-se que características apontadas na literatura como pertencentes a essa classe de trabalhadores foram confirmadas, como a precarização do trabalho para homens e mulheres e questões relacionadas ao gênero, como menores salários e nível de escolaridade detectados no extrato feminino da amostra. Porém, também foram obtidos dados que permitiam o aprofundamento da temática.
\end{abstract}

Palavras-chave: Bem-estar. Terceirização. Universidade Federal de Viçosa.

\begin{abstract}
The study aimed to develop a characterization of the socioeconomic profile of outsourced workers in public institutions, as well as their relationship with well-being at work at the Federal University of Viçosa (UFV). A brief historical contextualization was carried out about outsourcing, its unfolding as the precariousness of work and its effects on well-being at work, seeking to obtain data on their satisfaction at work, whether labor rights were being denied, the importance of work and the existence of these rights for these workers. The analysis was carried out with 90 workers outsourced in 2013 from the campus, based on indicators collected through a questionnaire on the socioeconomic profile and the apprehension of workers' well-being, based on parameters in the literature. The data were analyzed in a statistical-descriptive way in the specialized software STATA. It was observed that characteristics pointed out in the literature as belonging to this class of workers were confirmed, such as the precariousness of work for men and women and issues related to gender, such as lower wages and level of

\footnotetext{
1 Mestre em Economia Doméstica pela Universidade Federal de Viçosa, Professor no curso de Psicologia da Faculdade Dinâmica. E-mail: m.aureliomcc@hotmail.com Orcid: https://orcid.org/0000-0001-9749-3275

2 Doutora em Engenharia de Produção pela Universidade de São Paulo, Professora Adjunta da Universidade

Federal de Viçosa, Viçosa, MG, Brasil. E-mail: acsbifano@gmail.com Orcid: https://orcid.org/0000-0002-9046-9149

3 Doutora em Demografia pela Universidade Federal de Minas Gerais. Professora do Departamento de Economia Doméstica da Universidade Federal de Viçosa. Viçosa, MG, Brasil. E-mail: marciabfontes@gmail.com Orcid:

https://orcid.org/0000-0002-0400-9307

${ }^{4}$ Doutor em Economia Doméstica pela Universidade Federal de Viçosa, Professor Efetivo do Instituto Federal de Educação, Ciência e Tecnologia do Sudeste de Minas Gerais, campus Rio Pomba. E-mail: bruno.olher@ifsudestemg.edu.br Orcid: https://orcid.org/0000-0002-3707-3065
} 
education detected in the female extract of the sample. However, data were also obtained that allowed the deepening of the subject.

Keywords: Wellness. Outsourcing. Federal University of Viçosa.

\section{Resumen}

El estudio tuvo como objetivo desarrollar una caracterización del perfil socioeconómico de los trabajadores subcontratados en instituciones públicas, así como su relación con el bienestar en el trabajo en la Universidad Federal de Viçosa (UFV). Se realizó una breve contextualización histórica sobre la subcontratación, sus consecuencias como la precariedad laboral y sus efectos en el bienestar en el trabajo, buscando obtener datos sobre la satisfacción laboral, si se están negando derechos laborales, cuál es la importancia de y la existencia de estos derechos para estos trabajadores. El análisis se realizó con 90 trabajadores subcontratados en 2013 en el campus, a partir de indicadores recogidos a través de un cuestionario sobre el perfil socioeconómico y la aprehensión del bienestar de los trabajadores, con base en parámetros de la literatura. Los datos fueron analizados de forma estadístico-descriptiva en el software especializado STATA. Se observó que se constataban características señaladas en la literatura como pertenecientes a esta clase de trabajadores, como la precariedad laboral para hombres y mujeres y cuestiones relacionadas con el género, como menores salarios y nivel educativo detectados en la muestra de mujeres. Sin embargo, también se obtuvieron datos que permitieron profundizar en el tema.

Palabras clave: Bienestar. Subcontratación. Universidad Federal de Viçosa.

\section{INTRODUÇÃO}

A crise estrutural que vem acompanhando o modelo de produção capitalista, tem impulsionado várias transformações no mundo do trabalho, seja na sua natureza e performance, ou nos modos de organização da gestão e da produção para a sua sobrevivência (ANTUNES, 2015). Desde 1960, o modelo taylorista-fordista de organização produtiva, até então hegemônico, encontra-se em decadência por não manter os níveis de produção, acarretando desdobramentos, dentre os quais pretende-se destacar duas situações: (1) a reorganização da produção no modelo Toyotista, que visava otimizar os custos a partir da redução do número de trabalhadores, implantando sistemas de produção em células e just in time, e (2) a adoção do processo de gestão por meio de terceirizações, que se constitui na delegação dos processos que não são considerados parte estratégica do negócio a terceiros. (SALM e FOGAÇA, 1995).

No Brasil, a reestruturação produtiva teve início a partir da década de 1990, num contexto de industrialização instável e atrasado, cuja adoção do modelo Toyotista levou à flexibilização das relações de trabalho que permitiu a terceirização em grande escala (SOUZA e MENDES, 2016). Mesmo com objetivos diferentes no Brasil, o processo de terceirização vem ocorrendo tanto no setor privado, cuja meta é a ampliação do lucro, quanto nos órgãos públicos, cujo objetivo é a redução de gastos. Neste último caso, o processo se encontra em 
andamento mesmo com certa resistência por parte das organizações (HERNANDEZ e PEÑALVER, 2012).

Em se tratando do setor público especificamente, o início do processo de regulamentação das terceirizações inicia-se em 1967, com a promulgação do Decreto Lei 200/1967. Este marco foi sucedido por demais regulamentações que promoveram, dentre outros, a extinção do cargo público dos serviços gerais e de limpeza, em 1998, até os dias atuais.

Os últimos marcos regulamentares que tratam sobre a terceirização são as Leis 13.429 e 13.467, ambas de 2017 e o Decreto 9.507 de 2018 (SANTOS, 2017; BRASIL, 2018). A Lei 13.429/2017 trata da permissão para a terceirização para todos os cargos e funções, tanto no setor privado quanto público; a Lei 13.467/2017 altera a Consolidação das Leis Trabalhistas (CLT) nos pontos que tratam da terceirização no que concerne às relações jurídicas de emprego e às regras processuais na justiça do trabalho; e o Decreto 9.507/2018 regulamenta a proibição da terceirização de serviços que envolvam tomada de decisão e planejamento, coordenação e controle de instituições e órgãos de setores estratégicos e relacionados a conhecimento e tecnologia (incluindo as Instituições Federais de Ensino Superior - IFES) (ANTUNES e DRUCK, 2013; SANTOS, 2017; LOBO e SILVA, 2017; BRASIL, 2018).

Sob a ótica da administração, a terceirização é vista como uma ferramenta benéfica, pois, acredita-se que os níveis de produtividade e competitividade das empresas podem ser aumentados mediante a adoção desta prática. Desta forma, justifica-se que a terceirização seria um eficiente instrumento de gestão, tanto no setor público quanto no privado, permitindo que as instituições se especializem nas atividades consideradas estratégicas por terem papel central no negócio da empresa, possibilitando redução dos custos e elevando o número de empregos (COSTA, 2017).

Entretanto, existem críticas relativas à terceirização, como uma ferramenta na qual as organizações buscam otimizar seus ganhos financeiros, produtivos e competitivos, reduzindo seus custos isentando-se da responsabilidade pelo trabalhador, criando, desta forma, um processo de desverticalização, a partir da redução de níveis hierárquicos, e desterritorialização, ruptura do elo do indivíduo com seu território, da prática produtiva, que, por sua vez, gera o fenômeno de precarização das condições de trabalho (ANTUNES, 2015).

Estudos têm demonstrado (ALVES, 2010; ALVES, 2017; ANTUNES, 2015; DRUCK, 2016; DRUCK, 2018), que o trabalhador terceirizado possui condições de trabalho "de segunda categoria", assim como a própria remuneração. Antunes e Druck (2013) comparam o trabalho 
terceirizado ao trabalho escravo, com carga horária de trabalho maior e mais intensa, além de maior rotatividade; sofrem, ainda, discriminação tanto por parte da instituição contratante, quanto daqueles trabalhadores que possuem contratos diretos, estes últimos, se percebem com superiores aos terceirizados.

Diante desse quadro se pergunta, se o mesmo quadro ocorre em IFES instaladas no interior, afastadas dos grandes centros urbanos, cidades de médio e pequeno porte apresentariam esse mesmo modelo de precarização? Os trabalhadores sofreriam os mesmos tipos de preconceitos e de sofrimento no trabalho?

Para tanto, este estudo de caso foi desenvolvido utilizando-se dados dos trabalhadores terceirizados do setor de limpeza, da Universidade Federal de Viçosa - UFV, campus Viçosa. A cidade está localizada na zona da mata mineira, com uma população de 78.846 habitantes, caracterizando-se com uma cidade de médio porte (IBGE, 2019). Objetivando-se conhecer os trabalhadores terceirizados a partir de seu perfil socioeconômico, bem como sua relação com o bem-estar no trabalho, em específico, os trabalhadores terceirizados de serviços gerais da Universidade Federal de Viçosa (UFV).

\section{A TERCEIRIZAÇÃO ENQUANTO FERRAMENTA PARA FLEXIBILIZAÇÃO}

A discussão teórica apresentada nesta pesquisa teve como finalidade contextualizar a terceirização no cenário brasileiro, abordando os desdobramentos e efeitos sobre o trabalhador e sobre o trabalho, além de buscar discutir o conceito de bem-estar, suas caraterísticas e seu indicadores.

O modelo de produção capitalista composto pelo taylorismo e fordismo, hegemônico até então, começou a declinar a partir da década de 1970. Este processo se deu pelo fato de que estes modelos não conseguiam mais atender às demandas e aos interesses do capital, devido a uma redução constante no consumo, que, por sua vez, foi causada pelo desemprego estrutural que se instalava (ANTUNES, 2000).

A partir deste momento, os capitais financeiros começaram a ser aceitos no mercado internacional, e a crise fiscal do Estado capitalista levou a um processo que viria a ser entendido como o período de privatizações, na busca da redução de gastos, transferindo estes (gastos) para o capital privado. Neste processo de mudança e redução de custos, revelou-se uma reorganização do capital e de seu sistema ideológico, trazendo à tona o que se entendeu como o neoliberalismo, que promovia a privatização do Estado e um forte processo de 
reestruturação produtiva e do trabalho, cujas características principais foram a ampliação do processo de terceirização e consequente precarização do trabalho (ANTUNES, op. cit.)

Assim como outros fenômenos sociais ocorridos ao longo da história, a flexibilização do trabalho se tornou tema de debates e pesquisas, pois, modificou de forma significativa as relações de trabalho. Com o crescimento do mercado de trabalho e da oferta de mão de obra pela entrada dos jovens e mulheres, assim como inovações de tecnologia, os meios e modos de trabalho, anteriormente adotados, se tornaram obsoletos e foram substituídos por modelos de organização que visam diminuir gastos (VARGAS e MONSALVE, 2016).

Se configura, desta forma, um novo trabalhador, aquele que opera sua força de trabalho de forma terceirizada, subcontratada ou temporária, criando uma grande força de trabalho reserva na sociedade. Como consequência deste processo, a solidificação de políticas neoliberais foi realizada em países periféricos a partir da assinatura do Consenso de Washington, que visava estabelecer medidas de regulagem estrutural, com o intuito de desregular os mercados, privatizar o setor público e reduzir o tamanho do Estado (ANTUNES, ALVES, 2004). O processo de globalização econômica se amplia, apoiando-se no modelo Toyotista de produção, aproveitando sua característica de produção flexível, que busca atender e se adaptar às demandas do mercado.

A terceirização é também um fenômeno relacionado à flexibilização das leis trabalhistas para a gestão de mão de obra, possibilitando às empresas a contratação direta de funcionários apenas para as atividades fins, que são aquelas consideradas estratégicas, ligadas ao negócio principal da empresa, aos seus objetivos finais, como, por exemplo, setor de desenvolvimento e também a montagem final de produtos e contratando, indiretamente, empresas ou pessoas autônomas para lidar com os demais processos necessários, as atividades consideradas meio, como por exemplo uma peça de motor, a produção de bancos, ou serviços de limpeza, fornecimento de refeição(ões), ou segurança (VARGAS e MONSALVE, 2016).

A terceirização ganhou apelo mundial, sendo adotada tanto por organizações privadas quanto por Estados, em sua esfera administrativa. O modelo neoliberal que preconiza um Estado enxuto, ampliando as áreas da atuação da iniciativa privada, assim como promove a ausência do Estado do "mundo produtivo", apoia, também, o aumento da produtividade por meio da flexibilização das leis trabalhistas, o que, por consequência, além de incrementar a acumulação capitalista, aumenta também a exploração do sujeito que trabalha, o que acarreta sobrecarga física, emocional e social (CAMPOS; VIANA, 2015). 
Em termos jurídicos, a terceirização teve um grande apoio por meio da portaria 331 do Tribunal Superior do Trabalho (TST), que permitia a terceirização para atividades meio da empresa, e proibia para as atividades fim, o que foi posteriormente modificado e ampliado através das Leis 13.429 e 13.467, ambas de 2017 (DRUCK, 2016). ${ }^{5}$

Os principais pontos que tornam a terceirização atraente são a flexibilização do trabalho e a isenção das responsabilidades previstas na Consolidação das Leis Trabalhistas (CLT), gerando custos menores para a empresa. Observa-se também que, de maneira preponderante, os trabalhadores terceirizados têm um salário menor, maior carga horária de trabalho, estão suscetíveis a maior risco de acidentes e possuem menos direitos trabalhistas. Em adição, a grande parte dos acidentes que acontecem com os trabalhadores terceirizados não são contabilizados nos controles sociais do governo sobre trabalho no país (Sistema Nacional de Emprego-SINE; Sistema de Vigilância de Acidentes de Trabalho-SIVAT; Sistema Único de Saúde-SUS) registrando-se que os ramos com mais acidentes fatais são a petroquímica, a eletricidade e a construção civil (DRUCK, 2016).

As precarizações possíveis consideradas neste trabalho referem-se às relações sociais que os trabalhadores constroem no ambiente de trabalho, sua subjetividade e sua autopercepção de bem-estar no trabalho, seja no setor público, ou privado. A relação que o funcionário terceirizado vivencia com os não terceirizados no local de trabalho, ao ser contratado por uma empresa empregadora e trabalhando nas instalações da contratante do serviço, é de diferenciação, já que se trata de organizações com objetivos, funcionamentos, setores e tipos de vínculo empregatício diferentes, logo, essa diferenciação se resume no sentimento de não pertencimento e autopercepção negativa do trabalhador terceirizado, que apesar de trabalhar naquele local, não tem vínculo empregatício com o mesmo. Em se tratando de coletivismo de trabalho, a terceirização acarreta uma fragmentação que impede esta coletividade de existir, produzindo então uma disputa entre os trabalhadores que convivem e tem suas atividades no mesmo espaço e mesmas funções, pelo simples fato de usar um uniforme, crachá ou outra identificação que os diferenciam (ANTUNES e DRUCK, 2013).

No caso brasileiro, a implantação do modelo neoliberal se deu nos anos de 1990, quando o Brasil, enquanto país com baixo desenvolvimento tecnológico, era um local onde este modelo poderia ser amplamente explorado e ter suas leis alteradas. Nesta reestruturação produtiva brasileira ocorreram mudanças importantes, como a criação dos contratos

\footnotetext{
${ }^{5}$ Atividade meio é aquela ligada ao suporte da atividade principal, como limpeza e segurança; a atividade fim é aquela ligada a atividade principal da organização (BONFIM, GOMES, 2016).
} 
temporários. Na administração pública, iniciou-se o processo de extinção de cargos públicos, cortes nas organizações estatais e privatizações, políticas de ajuste fiscal, implementação de políticas públicas com aspecto paliativo e com foco de promover o aumento da mão de obra terceirizada (CAMPOS; VIANA, op. cit.).

Segundo Druck, Sena, Pinto, et al. (2018) a terceirização na administração pública não é um "processo recente, muito menos antigo", pois vem se modificando e se adaptando ao longo dos anos através dos governos e da sociedade, incluindo as Instituições Federais de Ensino Superior (IFES).

De acordo com os dados do estudo desenvolvido por Druck, Sena, Pinto et. al. (2018), desenvolvido com trabalhadores terceirizados em IFES, 94\% dos trabalhadores dos serviços de limpeza recebem um salário mínio; 61,9\% moram em regiões periféricas; 46\% não tiraram férias desde que foram trabalhar na universidade; 94\% responderam possuir os direitos sobre vale transporte e alimentação; seu relacionamento com seus colegas de trabalho e com os estudantes é considerado bom, porém, quase um quarto dos trabalhadores alegaram já terem sofrido alguma discriminação devido à sua posição de trabalho enquanto terceirizado. A autora conclui que o sentimento de pertencimento destes trabalhadores é maior em relação à universidade na qual prestam serviço, e não com a empresa na qual possuem o vínculo de trabalho.

\section{O BEM-ESTAR}

O bem-estar no trabalho é um estado almejado mediante a valorização do trabalhador enquanto pessoa, levando em consideração suas questões individuais, tais como, satisfação com o trabalho realizado, necessidades pessoais, sentimentos relativos ao trabalho, qualidade das relações sociais que se estabelecem no local de trabalho, engajamento e motivação. Se busca o equilíbrio saudável entre o trabalhador e a empresa, no intuito de que ambos possam ter suas necessidades atendidas e satisfeitas (ALVES, 2010).

Nas áreas do conhecimento que estudam o tema do bem estar, tais como, Psicologia, Administração, Ergonomia e Ciências Sociais, existem alguns fatores em comum, sendo: 1) o conjunto de estruturas organizacionais e práticas que são relevantes para o bem-estar do trabalho do trabalhador; 2) os processos de interpretação e/ou desempenho realizados pelo trabalhador na sua situação de emprego; 3) grau de ajustamento, correspondência ou concordância que se realiza entre o trabalhador e o trabalho que tem de fazer; 4) os diferentes 
elementos componentes e a estrutura interna de bem-estar no trabalho que experiência o trabalhador (GRANADOS, 2011).

É possível considerar o bem-estar sob duas perspectivas, uma que se refere ao ambiente de trabalho (objetivo), e outra que se refere à experiência psicológica dos trabalhadores (subjetivo). Para a dimensão objetiva, diversos fatores são elencados como itens que influenciam em uma boa ou má qualidade de vida no trabalho, com, por exemplo, o contexto do ambiente físico, fadiga física, risco à acidentes, dificuldade de operação de artefatos ou equipamentos e na realização das tarefas, assim como as condições do ambiente contratual. (GRANADOS, op. cit.).

As condições subjetivas dizem respeito aos problemas enfrentados dentro do local, como conflitos interpessoais e dificuldades de relacionamento, a falta da atividade individual e profissional que seria a possibilidade de desenvolver seu conhecimento e alcançar metas profissionais, o funcionamento da organização e função política interna, falta de confiança, segurança, comunicação interna ruim na empresa e falta benefícios (GRANADOS, op. cit.).

Outro ponto que interfere no bem-estar dos indivíduos terceirizados é a precarização das condições de trabalho. Como relatado, as formas gerenciais e as relações no trabalho são grandes influenciadoras no que diz respeito ao nível do bem-estar. Estas formas e relações geram situações e inadequações no trabalho, que por sua vez são os causadores dos processos de adoecimento e acidentes. A saúde do trabalhador pode ser influenciada por fatores que vão desde o estilo e processos da gestão até as condições e as relações que ele possui no local de trabalho, porém, é importante considerar que sua saúde também é influenciada consideravelmente por fatores externos ao contexto laboral, principalmente, socioeconômicos (DUTRA, COSTA, SAMPAIO, 2016).

Entre os órgãos internacionais que se preocupam com estas questões, a Organização Pan-Americana de Saúde (OPAS), considera que o local de trabalho é um dos principais locais para a promoção de ações em saúde, pois as pessoas tendem a passar em média um terço de suas vidas no ambiente de trabalho. Este serviço de promoção à saúde é considerado como primário para o desenvolvimento social, econômico e pessoal (CASAS e KLIJN, 2006).

É conveniente destacar que ser saudável não significa apenas a ausência de alguma doença, mas abarca os aspectos psíquicos e sociais, além dos físicos. A Organização Mundial de Saúde (OMS) define que o conceito de saúde é "um estado de completo bem-estar físico, mental e social e não somente ausência de afecções e enfermidades", e a promoção da saúde é a capacidade do indivíduo de controlar os processos que implicam em danos ou a melhorias 
à saúde. Assim, tanto para a OMS quanto para a OPAS a promoção da saúde no ambiente de trabalho é uma tentativa de aumentar o controle sobre as variáveis que afetam a mesma, contribuindo para uma melhoria econômica e psicossocial das pessoas. (CASAS e KLIJN, op. cit.; OMS, 2000).

É válida a reflexão de que se o trabalhador brasileiro está inserido em um contexto socioeconômico desfavorável para a promoção e manutenção de sua saúde, o trabalho se torna o local em que ele poderia buscar essa melhoria e bem-estar. Quando as condições de trabalho também se encontram desfavoráveis ou danosas e expõe o trabalhador a riscos, que levam a uma grande insatisfação e queda em seu bem-estar geral, potencializam-se as chances de desenvolver doenças físicas ou psicológicas (DUTRA, COSTA, SAMPAIO, 2016).

\section{MÉTODO}

O presente estudo é caraterizado como quantitativo-descritivo. Os dados analisados foram classificados como secundários, sendo retirados do banco de dados da pesquisa de mestrado de Olher (2013), que teve como população os trabalhadores terceirizados das Instituições Federais de Ensino da Zona da Mata Mineira.

No universo total da pesquisa, calculado em abril de 2013, constava a presença de 1.901 trabalhadores terceirizados, sendo entrevistados deste universo pelo autor, 351 pessoas nos seis campi pesquisados.

Para este estudo, realizou-se um recorte, utilizando-se, da amostra original de 351 participantes, os trabalhadores terceirizados lotados na Universidade Federal de Viçosa (UFV) campus Viçosa, que somaram um total de 90 participantes. Em relação ao questionário, do total de 35 questões, foram selecionadas 17 questões, consideradas pertinentes ao objetivo deste artigo, sendo elas citadas a seguir como categorias.

Para caracterizar o perfil socioeconômico dos trabalhadores foram utilizadas as seguintes categorias: idade; gênero; escolaridade; número de filhos; renda familiar; se o emprego era o primeiro com carteira assinada.

Com base sob as perspectivas objetivas e subjetivas, foram utilizados como variáveis para medir o bem-estar no trabalho as seguintes categorias: tempo de serviço na empresa, por considerar estabilidade e segurança acerca do seu cargo e emprego; oportunidade de crescimento ou incentivo a qualificação; grau de satisfação ao trabalhar no campus; se a empresa oferece equipamento de proteção Individual (EPI); se a empresa oferece uniformes; 
se a empresa oferece plano de saúde; se a empresa oferece alimentação ou vale alimentação; se a empresa oferece transporte ou vale transporte; qual era o nível de satisfação com seu salário; como o trabalhador classificava sua relação com os alunos do campus; como o trabalhador classificava sua relação com os servidores públicos do campus.

Para o tratamento dos dados, utilizou-se a estatística descritiva, com o suporte do software STATA, um programa para análise estatística amplamente utilizado em pesquisas na área das ciências sociais aplicadas (SOUSA e SILVA, 2000).

Para avaliar a ocorrência de influência entre variáveis, procedeu-se ao teste de correção linear de Pearson (r), entre idade e gênero, gênero e escolaridade, idade e renda, escolaridade e renda, e, por fim, escolaridade e idade.

Os resultados serão apresentados utilizando-se gráficos e tabelas.

\section{RESULTADOS E DISCUSSÕES}

\section{CARACTERÍSTICAS SOCIOECONÔMICAS}

As variáveis utilizadas para a composição do perfil socioeconômico nesse estudo foram: (a) gênero; (b) idade; (c) grau de escolaridade; (d) número de filhos; (e) renda familiar; (f) primeiro emprego com carteira assinada.

Tabela 1- Dados sobre características socioeconômicas, segundo indicadores da pesquisa, 2013.

\begin{tabular}{|c|c|c|}
\hline Características socioeconômicas & $\%$ & (continua) \\
\hline \multicolumn{3}{|l|}{ Sexo } \\
\hline Masculino & & 50 \\
\hline Feminino & & 50 \\
\hline \multicolumn{3}{|l|}{ Idade } \\
\hline Até 30 anos & & 29 \\
\hline De 31 a 40 anos & & 44 \\
\hline De 41 a 50 anos & & 16 \\
\hline De 51 a 60 anos & & 10 \\
\hline Mais de 60 anos & & 1 \\
\hline \multicolumn{3}{|l|}{ Escolaridade } \\
\hline Ensino fundamental incompleto & & 19 \\
\hline Ensino fundamental completo & & 17 \\
\hline Ensino médio incompleto & & 14 \\
\hline Ensino médio completo & & 37 \\
\hline Ensino superior incompleto & & 8 \\
\hline Ensino superior completo & & 2 \\
\hline Pós-graduação & & 2 \\
\hline
\end{tabular}




\begin{tabular}{cc}
\hline Abstenção & 1 \\
\hline Número de filhos & 29 \\
Não possui & 29 \\
1 filho & 26 \\
2 filhos & 12 \\
3 filhos & 2 \\
4 filhos & 1 \\
5 filhos ou mais & 1 \\
Abstenção & 7 \\
Renda familiar & 48 \\
Até 1 Salário Mínimo & 37 \\
Até 2 Salários Mínimos & 5 \\
De 2 a 5 Salários Mínimos & 2 \\
De 5 a 10 Salários Mínimos & 1 \\
Prefiro não responder & \\
Abstenção & \\
Este é o primeiro emprego com & 74 \\
carteira assinada? & 26 \\
Não & 2013 \\
Sim &
\end{tabular}

Fonte: Dados da pesquisa, 2013

Sobre a idade, buscou-se averiguar qual foi a faixa etária mais presente em cada segmento de renda. Contata-se que existe uma concentração maior de trabalhadores na faixa de 31 a 40 anos, sendo que 24 são mulheres, enquanto os homens estão em maior número na faixa até 30 anos, correspondendo a 17 trabalhadores. Como apresentado na Tabela 1, os trabalhadores estão divididos em 50\% para cada sexo; 44\% dos trabalhadores terceirizados do campus UFV Viçosa possuem de 31 a 40 anos, 29\% possuem até 30 anos, 16\% de 41 a 50 anos; $10 \%$ possuem entre 51 a 60 anos e apenas 1\% possui mais de 60 anos.

Quando se trata do gênero, homens e mulheres se apresentam em proporções iguais, sendo 45 homens e 45 mulheres. São, em sua maioria, pessoas com até 40 anos de idade, representando uma faixa da população economicamente ativa (PEA) e em seu auge de capacidade de trabalhar. Por se tratar de um serviço de média a alta exigência física e por existir um preconceito contra esta classe de trabalhadores, pessoas com 60 anos ou mais tendem a não permanecer neste emprego (FELIX, 2016).

Estes dados são coerentes com o que se observa no cenário demográfico brasileiro, com base no evento denominado "bônus demográfico", onde aproximadamente dois terços da população total estão em idade considerada economicamente ativa (PEA), que vai dos 15 aos 64 anos. Este cenário é propício para o crescimento da oferta da produção de bens e serviços a nível nacional, refletindo justamente o aumento de pessoas na condição de trabalhadores terceirizados no setor de serviços como o de limpeza (CORRÊA, GONÇALVES, SANTOS, et al., 2016). 
Em relação à escolaridade, vê-se que a maioria possui até o ensino médio, somando $87 \%$ do total da população, sendo que 37\% possuem ensino médio completo, 14\% finalizaram o ensino fundamental, mas, apesar de ingressarem no ensino médio, não concluíram; 17\% possuem ensino fundamental completo e não ingressaram no ensino médio e 19\% iniciaram, mas não concluíram o ensino fundamental. Em 8\% dos casos, os trabalhadores iniciaram 0 ensino superior, mas não concluíram, $2 \%$ possuem graduação e pós-graduação. Os dados indicam que tanto os homens como mulheres possuem, em sua maioria, ensino médio completo. Observamos que as mulheres estão em número um pouco maior nos ensinos médio, fundamental e médio incompletos. Destaca-se que quanto menor a idade, maior é mais frequente nível de instrução mais elevado, estando entre ensino médio incompleto até ensino superior.

Em sua maioria, trabalhadores e trabalhadoras de serviços de limpeza, cursaram até o ensino médio. Trabalhadores e trabalhadoras que possuem ensino médio completo recebem em sua grande maioria até dois salários mínimos. Os que ganham entre dois e cinco salários possuem ensino médio completo. Os que possuem renda de um salário mínimo possuem a menor escolaridade. Segundo dados da Associação Brasileira de Empresas e Pesquisa (ABEP, 2018), baixa escolaridade pode estar diretamente relacionada à renda entre as classes $\mathrm{B}$ e $\mathrm{C}$. Destaca-se que a classe trabalhadora terceirizada possui uma remuneração em média $27 \%$ menor do que os servidores públicos na mesma função (ANDRETA e CAMPOS, 2015; ALVES, 2017).

As mulheres são em maior número em comparação aos homens, no ensino fundamental incompleto, médio completo e médio incompleto e também no ensino superior incompleto. Os resultados mostram que no geral, os homens têm um nível de escolaridade menor. Os estudos de Queiroz et al. (2017), Jesus e Barbosa (2016) e os dados do IBGE (2010) corroboram com estes resultados. Nos dados nacionais (IBGE, op. cit.) os homens acima dos 25 anos, em $50,8 \%$ dos casos, possuem fundamental incompleto e 9,9\% com superior completo, enquanto as mulheres possuem 47,8\% e 12,5\% respectivamente. Porém, de acordo com os dados do IBGE (2016) as mulheres tendem a evadir, principalmente devido a fatores econômicos, em $26,1 \%$ dos casos, pois, elas tendem a deixar os estudos para trabalhar ou realizar trabalho doméstico.

Pode-se constatar que para exercer o cargo de auxiliar de serviços gerais é exigido menor nível de escolaridade. As pessoas com até 30 anos se concentram entre ensino médio incompleto e completo e quanto mais velho for o trabalhador, menor seu grau de escolaridade, 
o que representa ainda um reflexo da baixa escolaridade a nível nacional no Brasil. No último censo (IBGE, 2010) 49,3\% da população nacional acima de 25 anos não havia concluído o ensino fundamental. Considerando apenas as pessoas residentes em áreas urbanas, este índice era de 44,2\% da população, a 79,6\% de pessoas residentes em áreas rurais. Estes resultados concordam com a literatura, quando se diz que estes trabalhadores são vistos como de segunda classe e possuem baixa escolaridade, apresentando, de acordo com Antunes e Druck (2013) uma baixa remuneração, que por sua vez, pode influenciar no bem-estar geral do cotidiano familiar destes trabalhadores, sendo delimitador de oportunidades, de bens, planejamento familiar e serviços de lazer, saúde e educação.

Ainda segundo os dados do censo 2010, ocorreu um aumento do nível de instrução das pessoas com menos de 25 anos, o que está refletindo em uma mudança na renda per capita destas famílias quando este jovem com maior escolaridade entra no mercado de trabalho. $O$ percentual de famílias com integrantes de 25 anos ou mais, com renda familiar maior de 5 salários mínimos saltou de 1,1\% para 33,9\%. Este fator se liga aos trabalhadores da pesquisa pelo fato destes estarem entre aqueles que ao atingirem a idade de 31 a 40 anos estarão com a renda entre 2 a 5 salários mínimos.

Em relação ao número de filhos, 29\% relataram não possuir filhos, 29\% um filho, 26\% dois filhos, $12 \%$ três filhos, $2 \%$ quatro filhos e $1 \%$ cinco ou mais filhos.

No que diz respeito à renda familiar, $48 \%$ dos participantes relataram renda familiar até dois salários mínimos $6,37 \%$ de dois a cinco salários, $7 \%$ um salário mínimo e $5 \%$ de cinco a dez salários; 7\% preferiram não responder. Tanto os homens quanto as mulheres declararam renda até dois salários mínimos, tendo como segunda resposta mais frequente de dois a cinco. O que indica que trabalhadores de serviços gerais, estão no intervalo que compreende as classes média e baixa. Destaca-se a frequência de mais mulheres do que homens com renda de até um salário mínimo. À medida que a renda aumenta, nas faixas de 2 a 5 salários e de 4 a 10 salários, a presença de mulheres se reduz. Trabalhadores na faixa de 18 a 30 e de 31 a 41 em sua maioria, possuem renda de até dois salários mínimos; os trabalhadores na faixa de 41 a 50 anos são os que em sua maioria, possuem renda de um salário. Em termos de empregabilidade, para aproximadamente $74 \%$ dos trabalhadores terceirizados, esta não era a primeira experiência com carteira assinada.

Grande parte dos trabalhadores que possuem renda de até dois salários mínimos, estão na faixa etária de até 40 anos, porém, dentro deste grupo, existe um subgrupo onde a maioria

${ }^{6}$ O salário mínimo em 2013 era no valor de 678,00 Reais (Secretaria do Estado de Saúde, Governo de São Paulo, 2019). 
dos trabalhadores que possuem renda de dois a cinco salários mínimos estão situados, tendo entre 31 a 40 anos. Constata-se que, a diferenciação deste subgrupo, se dá à medida que a faixa etária aumenta, onde as pessoas com a renda de dois a cinco salários, tendem a ser maioria, abrindo a hipótese de que há um complemento da renda per capita familiar, seja por outra fonte de renda informal, aposentadoria ou até mesmo o suporte por parte dos filhos que ainda residem na mesma casa.

Esta hipótese se apoia no fato de grande parte destas pessoas estarem no grupo denominado PEA, pois, além de possuírem este trabalho, eles ou seus cônjuges podem ter outra fonte de renda extra, que serve de complemento para suprir as necessidades da família. Entre 2004 e 2014 o país passou por um aumento nas vagas do setor de prestação de serviço, aproveitando o fato de 85\% da PEA residem em centros urbanos (LÚCIO, 2015).

Em todas as faixas de renda o número de pessoas mais velhas é menor. O que sugere que o setor de serviços foi um dos afetados pela mudança econômica e demográfica, revelando que o mercado de trabalho para este segmento é altamente influenciado pela idade, buscando preferencialmente aqueles que possuem até 40 anos (CORRÊA, GONÇALVES, SANTOS, et al., 2016, DELLINK, 2016).

O número de mulheres ganhando até dois salários mínimos é maior. À medida que aumenta o salário, diminui o número de mulheres, reforçando assim o que outras pesquisas específicas sobre o tema apontam (QUEIROZ, GOLÇALVES, 2017; IBGE, 2018; PRONI, PRONI, 2018) que as mulheres tendem a ganhar menos que os homens no mercado de trabalho. Essa desigualdade de renda é um reflexo de preconceito de gênero que ainda existe no Brasil, onde segundo Proni e Proni (op. cit.) apesar da diferença média salarial entre homens e mulheres ter caído de 80,3\% em 2003 para 16,1\% em 2015, de acordo com o IBGE (op. cit.), as mulheres ainda recebem cerca de $3 / 4$ do que os homens recebem, sendo sua renda vista apenas como um complemento à renda familiar que é provida pelo marido.

Apesar de ser um trabalho de suporte aos demais, estes trabalhadores não são bem remunerados, o que pode interferir na sua motivação para realizar suas tarefas e permanecer no trabalho, além de estar diretamente relacionado à sua condição social.

\section{BEM-ESTAR NO TRABALHO}

As variáveis utilizadas para a avaliação do bem-estar no trabalho nesse estudo foram: (a) tempo de serviço na empresa, por considerar estabilidade e segurança acerca do seu cargo 
e emprego; (b) oportunidade de crescimento ou incentivo a qualificação; (c) grau de satisfação ao trabalhar no campus; (d) se a empresa oferece equipamento de proteção Individual como botas, luvas, óculos, entre outros (EPI); (e) se a empresa oferece uniformes; (f) se a empresa oferece plano de saúde; (g) se a empresa oferece alimentação ou vale alimentação; (h) se a empresa oferece transporte ou vale transporte; (i) qual era o nível de satisfação com seu salário; (j) como ele classificava sua relação com os alunos do campus; (k) como ele classificava sua relação com os servidores públicos do campus.

Tabela 2- Características de bem-estar.

\begin{tabular}{cc} 
Características de bem-estar & $\%$ \\
\hline Tempo de trabalho na empresa & 22 \\
Menos de 1 ano & 26 \\
Entre 1 e 2 anos & 42 \\
Entre 2 e 6 anos & 9 \\
Mais de 6 anos & 1 \\
Abstenção & 72 \\
Não crescimento & 16 \\
Sim, treinamentos & 10 \\
Sim, palestras & 1 \\
Plano de carreira & 1 \\
Outro & 10 \\
\hline Oportunidade ofe campus & 19 \\
Muito insatisfeito & 51 \\
Insatisfeito & 19 \\
Satisfeito & 1 \\
Muito satisfeito & \\
Abstenção &
\end{tabular}

Fonte: Dados da pesquisa, 2013

De acordo com os dados apresentados na Tabela 2, um quantitativo relativo a $42 \%$ dos trabalhadores está na empresa entre dois e seis anos; $26 \%$ entre um e dois anos, $22 \%$ a menos de um ano. Destaca-se que apenas $9 \%$ dos trabalhadores estão a mais de seis anos na empresa.

Em relação à oportunidade de crescimento ou incentivo à qualificação, aproximadamente $72 \%$ responderam não haver recebido nenhum tipo de incentivo, enquanto cerca de 16\%, informaram receber treinamentos para especialização e 10\% palestras motivacionais. Somente $1 \%$ relatou plano de carreira como incentivo.

Para a variável satisfação no trabalho, a tendência dos dados - 70\%, vão de satisfeito a muito satisfeito, enquanto $29 \%$ dos trabalhadores apresentaram uma tendência de insatisfeito a muito insatisfeito. 
Os demais indicadores sobre bem-estar, utilizados nesse estudo, serão apresentados na Tabela 3 a seguir.

\section{Tabela 3- Indicadores de Bem-Estar}

Indicadores

\begin{tabular}{ccc}
\hline & Sim (\%) & Não (\%) \\
\hline A empresa oferece EPI e uniforme & $69 \%$ & $31 \%$ \\
\hline A empresa oferece plano de saúde & $85 \%$ & $15 \%$ \\
\hline A empresa oferece alimentação & $76 \%$ & $24 \%$ \\
\hline A empresa oferece transporte ou vale \\
$\quad$ transporte?
\end{tabular}

Fonte: Dados da pesquisa, 2013.

Os dados apresentados na Tabela 3 dizem respeito aos indicadores do bem-estar no trabalho que foram avaliados entre "sim ou não". Todos os indicadores obtiveram um resultado maior para sim, variando entre $54 \%$ a $85 \%$. Destacando que os indicadores relacionados a questões mais subjetivas como satisfação com o salário e qualidade das relações interpessoais ficaram em torno de $50 \%$, bem menos que as questões relacionadas a fatores concretos/materiais, que giraram em torno de $70 \%$.

Quando se analisou as variáveis de bem-estar no trabalhado, percebeu-se a ocorrência de alta rotatividade. Quase metade do quadro está na empresa entre dois e seis anos. Este resultado aponta que não há uma continuidade e estabilidade por parte dos trabalhadores na empresa, visto que quase um quarto destes trabalhadores estão na empresa a menos de um ano. Essa instabilidade é considerada como um fator negativo, gerando insegurança para poder ingressar e desenvolver seu trabalho na empresa, contribuindo negativamente para o bem-estar (OLIVEIRA-MONTEIRO, SCACHETTI, VIEIRA, et. al., 2016).

Segundo Santos (2012), a satisfação pode ser entendida como uma emoção ou como uma atitude positiva perante as experiências vividas no trabalho. Assim, o fato de trabalhar no campus, corrobora de forma positiva sobre a satisfação dos trabalhadores e, por conseguinte, sobre o bem-estar, como discutido no estudo feito por Druck, Sena, Pinto, et al. (2018). Como 
apresentado, 70\% dos trabalhadores alegaram estar "satisfeitos ou muito satisfeitos", sugerindo que dentre as variáveis do ambiente, convívio social, remuneração e atividade de trabalho, o trabalhador considera positiva sua vivência, sendo então um dado semelhante ao encontrado por Druck, Sena, Pinto, et al. (op. cit.).

$\mathrm{Na}$ Tabela 3, foram elencados os indicadores de bem-estar que foram respondidas em "sim ou não". Todos os indicadores apresentam uma porcentagem de respostas maior para "sim", variando entre 54\% a $85 \%$, o que permitiu sugerir que o nível de bem-estar no trabalho para a maioria destes trabalhadores tende a ser positivo. Porém, observa-se que os indicadores que apresentaram os menores índices são aqueles considerados subjetivos (os indicadores de relações interpessoais e de segurança), que ficaram por volta dos $50 \%$, que pode ser ocasionada tanto por fatores relativos à estrutura da empresa, comparação com a chefia e colegas de trabalho, condições de trabalho ruins, impossibilidade de desenvolvimento profissional, falta de confiança nos colegas, chefia ou sobre si e até mesmo falta de benefícios ou de bônus que atendam suas necessidades pessoais em seu cotidiano familiar (GRANADOS, 2011; DRUCK, 2016).

A empresa oferece também uniforme, EPI, auxílio de transporte e alimentação que são equipamentos básicos de segurança e necessários para o bem-estar, por diminuir os riscos de acidentes. Apesar de constar na legislação trabalhista e ser um direito, observa-se a partir da Tabela 3, que nem todos os trabalhadores responderam possuir estes direitos, o que demonstra um descumprimento das leis trabalhistas e um fator que colabora para um baixo nível de bem-estar, visto estar diretamente ligado à precarização das condições de trabalho que podem levar tanto à insatisfação como a acidentes e adoecimentos (DUTRA, COSTA, SAMPAIO, 2016)

A empresa não oferece outros itens (não obrigatórios) que elevariam o bem-estar no trabalho, como por exemplo, o incentivo à qualificação, oportunidade de crescimento dentro da empresa e plano de saúde. Isto pode gerar, com o tempo, um sentimento de desvalorização por parte dos trabalhadores, que pode servir de base para questionamentos e sentimentos negativos acerca da utilidade de seu trabalho, confiança, sentimento de valorização e autoestima. A presença destes benefícios poderia ser um diferencial não apenas motivador para o trabalho, mas também uma oportunidade de melhora socioeconômica devido à promoção de sua saúde e de sua família (CASAS E KLINJ, 2006; DUTRA, COSTA, SAMPAIO, op. cit.) 
E, por fim, vale a menção de que pouco mais da metade dos trabalhadores se consideram "satisfeito" com seus salários, sugerindo que, devido às poucas oportunidades de emprego e ao nível de instrução e qualificação acadêmica, este é um emprego "justo".

Os resultados do teste de correlação linear de Pearson (r), para correlação entre variáveis idade e gênero, gênero e escolaridade, idade e renda, escolaridade e renda, e por fim, escolaridade e idade, mostraram não haver correlação entre nenhuma das variáveis citadas, obtendo respectivamente os resultados de $0.1034,-0.1054,-0.1066,-0.0097,0.9999$. Portanto, não existe influência considerada estatisticamente significativa entre estas variáveis.

\section{CONSIDERAÇÕES FINAIS}

Pode-se caracterizar o perfil socioeconômico dos trabalhadores terceirizados da UFV campus Viçosa com base nos descritores utilizados, concluindo que estas pessoas têm, em geral, até 40 anos de idade, recebem um (1) ou dois (2) salários mínimos, possuem um (1) ou dois (2) filhos e um baixo nível escolar, sendo as mulheres o grupo com maior investimento e nível escolar, mas também, com maior evasão escolar e uma menor renda.

Os resultados em relação ao bem-estar apontaram que, apesar de possuírem algumas condições mínimas previstas por lei, como uso de EPI, vale transporte e alimentação, não possuem incentivos e possibilidade de mudança, em termos de qualificação e de promoção. $O$ que aliado à alta rotatividade e insegurança no ambiente de trabalho, representa um importante fator de impacto negativo no bem-estar.

O trabalho em serviços gerais, em empresas terceirizadas, é, portanto, precarizado, desvalorizado e invisibilizado, o que compromete o bem-estar no trabalho e fora dele, à medida que afeta a autoestima das pessoas e sua disposição para a vida, devido aos processos de adoecimento fruto da organização do trabalho.

As políticas macroeconômicas e suas consequências chegam também às pequenas e médias cidades, aos moradores das periferias e das regiões rurais. Aos jovens, aos idosos, às mulheres. Em atividades de trabalho de baixo prestígio social, de baixa qualificação profissional e baixos salários, essas consequências são mais fortemente vivenciadas.

\section{REFERÊNCIAS}


ABEP, Associação Brasileira de Empresas de Pesquisa. 2008. Dados com base no Levantamento Sócio Econômico. Disponível em: http://www.abep.org/criterio-brasil. Acessado em: 02 de dez. 2018.

ALVES, E. F. Qualidade de vida no trabalho: indicadores e instrumentos de medidas. Diálogos \& Saberes, v. 6, n. 1, p. 77-87, 2010.

ALVES, G. Outsourcing: The future of labor in Brazil. Trabalho educação e saúde, Rio de Janeiro, v. 15, n. 2, p. 337-339, ago. 2017.

ANDRETA, R., L.; CAMPOS, R., S. Base da pirâmide social brasileira? O perfil dos trabalhadores terceirizados no contexto dos anos 2000. Revista da ABET, v. 14, n. 2, jul./dez., 2015.

ANTUNES, R. Os sentidos do trabalho: ensaio sobre a afirmação e a negação do trabalho. Org. Ricardo Antunes. 3ª ed. São Paulo: Boitempo Editorial, 2000.

ANTUNES, R. A sociedade da terceirização total. Revista da ABET, v. 14, n. 1, jan/jun, 2015.

ANTUNES, R.; ALVES, G. As mutações no mundo do trabalho na era da mundialização do capital. Educação e Sociedade, Campinas, vol. 25, n. 87, p. 335-351, maio/ago. 2004.

ANTUNES, R.; DRUCK, G. A terceirização como regra? Revista do Tribunal Superior do Trabalho, São Paulo, v. 79, n. 4, p. 214-231, out./dez. 2013.

BONFIM, B. K. S.; GOMES, A. V. M. Para além da discussão sobre atividade fim e atividade meio: A igualdade de direitos e a responsabilidade solidária como meios para a proteção do trabalhador terceirizado. Scientia luris, Londrina, v. 20, n. 2, p. 266-296, jul. 2016.

BRASIL. Lei no 9632, de 07 de maio de 1998. Dispõe sobre a extinção de cargos no âmbito da Administração Pública Federal direta, autárquica e fundacional, e dá outras providências. Diário Oficial da República Federativa do Brasil. Disponível em: http://www.planalto.gov.br/ccivil 03/Leis/L9632.htm. Acesso em nov. 2018.

CAMPOS, C. M. S.; VIANA, N.; SOARES, C. B. Transformations in contemporaneous capitalism and its impact on state policies: the SUS in debate. Saúde e sociedade, São Paulo, v. 24, p. 82-91, Jun. 2015.

CASAS, S. B.; KLIJN, T. P. Promoción de la salud y un entorno laboral saludable. Revista Latino-Americana de Enfermagem, Ribeirão Preto, v. 14, n. 1, p. 136-141, fev. 2006.

CORRÊA, A. et al. Impactos do bônus demográfico para gestão de pessoas. Revista de Administração FACES Journal, 2016.

DELLINK, R. et al. Long-term economic growth projections in the Shared Socioeconomic Pathways. OECD Environment Directorate, Paris, France. 2017.

DRUCK, G. Unrestrained outsourcing in Brazil: more precarization and health risks for workers. 
Caderno Saúde Pública, Rio de Janeiro, v. 32, n. 6, jun. 2016.

DRUCK, G. et al. A terceirização no serviço público: particularidades e implicações. Terceirização do trabalho no Brasil: novas e distintas perspectivas para o debate. Brasília. p. 113-142. 2018.

DUTRA, F. C. M. S.; COSTA, L. C.; SAMPAIO, R. F. A influência do afastamento do trabalho na percepção de saúde e qualidade de vida de indivíduos adultos. Fisioterapia e Pesquisa, São Paulo, v. 23, n. 1, p. 98-104, mar. 2016.

FELIX, J. O direito idoso e o mercado de trabalho. Política Nacional do Idoso: velhas e novas questões. Rio de Janeiro. Ipea. 2016. Cap. 8. Disponível em: $<$ http://www.ipea.gov.br/portal/index.php?option=com_content\&view=article\&id=28693>. Acesso em: 13/05/20119.

GIL, A. C.; Métodos e Técnicas de Pesquisa Social. São Paulo, Editora Atlas, 2008.

GRANADOS, I. Calidad de vida laboral: história, dimensiones y beneficios. Revista de Investigación en Psicología, v. 14, n. 2, p. 209-221, mar. 2014. ISSN 1609-7475.

HERNÁNDEZ, F., C.; PEÑALVER, A. J, B. La administración inteligente como fator para reducir el fracasso empresarial. Tourism \& Management, nํ 8, 2012.

IBGE, Instituto Brasileiro de Geografia e Estatística. PNAD Contínua, 2016. Disponível em: https://agenciadenoticias.ibge.gov.br/agencia-sala-de-imprensa/2013-agencia-denoticias/releases/18992-pnad-continua-2016-51-da-populacao-com-25-anos-ou-mais-do-brasilpossuiam-apenas-o-ensino-fundamental-completo. Acessado em: 25 de abril de 2019.

IBGE, Instituto Brasileiro de Geografia e Estatística. Estatísticas de gênero e indicadores sociais da mulher no brasil. Disponível em: <https://www.ibge.gov.br/estatisticas novoportal/multidominio/genero/20163-estatisticas-de-genero-indicadores-sociais-das mulheres-no-brasil.html?=\&t=0-que-e >. Acessado em: 02 de dez. 2018.

IBGE, Instituto Brasileiro de Geografia e Estatística. Disponível em: https://biblioteca.ibge.gov.br/visualizacao/livros/liv101551_informativo.pdf. Acessado em: 25 de abril de 2019.

IBGE, Instituto Brasileiro de Geografia e Estatística. Censo Demográfico 2010: educação e deslocamento. Disponível em: https://biblioteca.ibge.gov.br/visualizacao/periodicos/545/cd 2010 educacao e deslocamento. pdf. Acessado em 02/05/2019.

IBGE, Instituto Brasileiro de Geografia e Estatística. Panorama cidades. Junho, 2019. Disponível em: https://cidades.ibge.gov.br/brasil/mg/vicosa/panorama. Acessado em:20/05/2019

JESUS, C. S. B.; BARBOSA, R. J. S. Trabalho feminino x nível de escolaridade: uma análise sobre a influência da educação para a inserção da mulher no mundo do trabalho. Revista Ártemis, v. 21, pp.131-146, jan/jul 2016. 
LOBO, B. N. L.; SILVA, R. P. "Reforma trabalhista" e terceirização na administração pública: reflexões críticas. Revista do Tribunal Regional do Trabalho 3a Região, Belo Horizonte, edição especial, p. 457-469, nov. 2017.

LÚCIO, C. G. Desafios para o crescimento e o emprego. Estudos avançados, São Paulo, v. 29, n. 85, p. 21-33, dez. 2015.

MARCELINO, P.; CAVALCANTE, S. Por uma definição de terceirização. Caderno $\mathbf{C R H}$, Salvador, v. 25, n. 65, p. 331-346, ago. 2012.

OLHER, B. Terceirização das atividades de apoio em instituições federais de ensino da zona da mata de minas gerais. Dissertação De mestrado. Universidade Federal de Viçosa. Viçosa Minas Gerais. 2013.

OLHER, B. S.; COSTA, I. S.; TEIXEIRA, M. I. Reflexões sobre os efeitos da terceirização dos cargos de apoio no serviço público federal: estudo de caso no instituto federal do sudeste de MG campus Rio Pomba. Holos, ano 31, Vol. 5. Ago 2015.

OLIVEIRA-MONTEIRO, N. R. et al. Terceirização e estabilidade no emprego: estudo sobre a hierarquia de valores laborais de trabalhadores terceirizados. Cadernos de psicologia social do trabalho, São Paulo, v. 19, n. 1, p. 17-28, 2016.

OMS, OPS. Estrategia de Promoción de la salud en los lugares de trabajo de América Latina y el Caribe: Anexo № 6 - Documento de Trabajo. Ginebra. (Swz): Organización Mundial de la Salud; 2000.

PAULA, A. H.; Nutricionistas do ru/ufv: trabalho e qualidade de vida no contexto de terceirização parcial em ifes. 2017. Projeto de tese (Doutorado em Economia Doméstica). Universidade Federal de Viçosa. Viçosa, Minas Gerais, no prelo, 2017.

PRONI, T. T. R. W.; PRONI, M. W. Discriminação de gênero em grandes empresas no Brasil. Revista de Estudos Feministas, Florianópolis, v. 26, n. 1. 2018.

QUEIROZ, J. V.; GONÇALVES, L. A.; KRÜGER, G. N. Análise do grau de escolaridade das mulheres no brasil. Seminário Internacional Fazendo Gênero. 11 \& 13thWomen's Worlds Congress (Anais Eletrônicos), Florianópolis, 2017, ISSN 2179-510X.

SALM, C. L.; FOGAÇA, A. Questões críticas da educação brasileira. Consolidação de propostas e subsídios para ações nas áreas da tecnologia e da qualidade. MCT/Programa de Apoio à Capacitação Tecnológica da Indústria; MICT/Programa Brasileiro de Qualidade e Produtividade, 1995.

SANTOS, B. Satisfação no Trabalho: o caso de um Banco. Dissertação de mestrado (Mestrado em Gestão Estratégica de Recursos Humanos). Instituto Politécnico de Setúbal. Setúbal, Portugal. 2012.

SANTOS, J. A.; Cotidiano familiar e qualidade de vida de usuários dependentes de cuidado - Programa de saúde da família, Viçosa -MG. 2008. Dissertação (Mestrado em 
Economia Doméstica). Universidade Federal de Viçosa. Viçosa, Minas Gerais.

SECRETARIA DE ESTADO DA SAÚDE, Governo do Estado de São Paulo. Acesso em: 23/10/2019. Disponível em: http://www.saude.sp.gov.br/coordenadoria-de-recursoshumanos/areas-da-crh/grupo-de-gestao-de-pessoas/ggp/acervo-virtual/acontecendo/salariominimo. 2019.

SIMOES, P. H. C.; ALVES, J. E. D.; SILVA, P. L. N. Transformações e tendências do mercado de trabalho no Brasil entre 2001 e 2015: paradoxo do baixo desemprego? Revista brasileira de estudos populacionais, São Paulo, v. 33, n. 3, p. 541-566, dez. 2016.

SOUZA, H. S.; MENDES, Á. N. Outsourcing and "dismantling" of steady jobs at hospitals. Revista da escola de enfermagem. USP, São Paulo, v. 50, n. 2, p. 286-294, abr. 2016.

SOUSA, M. H.; SILVA, N. N. Comparação de softwares para análise de dados de levantamentos complexos. Revista de Saúde Pública, São Paulo, v. 34, n. 6, p. 646-653, dez. 2000.

VARGAS, C. P.; MONSALVE, M. E. Labor outsourcing: between efficiency and social equity. Revista Ces Derecho, Medellín, v. 7, n. 1, p. 3-10, jan. 2016. 